\title{
EFECTOS COLATERALES DE LA TRANSICIÓN AL FORMATIVO: UNA NUEVA CULINARIA ENTRE LOS CAZADORES-RECOLECTORES MARINOS DEL DESIERTO DE ATACAMA ${ }^{1}$
}

\author{
COLLATERAL EFFECTS OF THE FORMATIVE TRANSITION: THE NEW \\ CULINARY OF THE MARINE HUNTER-GATHERERS IN THE ATACAMA \\ DESERT
}

\author{
Itaci Correa ${ }^{2}$, Carolina Carrasco ${ }^{3}$, Benjamín Ballester ${ }^{4}$ y Francisco Gallardo 5
}

\begin{abstract}
En la Región de Antofagasta, el período Formativo se define por importantes transformaciones socio-económicas relacionadas al abandono paulatino del modo de vida cazador recolector. Sin embargo, para los habitantes de su costa árida, la caza y recolección marina siguieron siendo primordiales. A pesar de ello, experimentan significativos cambios culturales, como la incorporación de una tecnología de cocina foránea. El estudio de residuos adheridos al interior de una muestra de vasijas ofrendadas en los cementerios de túmulos litorales (2.500-1.200 cal a.p.) permite postular que la adopción de cerámica en la costa se ve relacionada a una nueva culinaria de vegetales cultivados, integrándose complementariamente a la tradicional alimentación basada en carnes marinas. La incorporación de estas nuevas recetas de mesa pueden ser vistas como efecto colateral de los procesos "formativos" vividos por los habitantes de valles y oasis del desierto interior, en el marco de un proceso de construcción socio-cultural compartido entre quienes vivían en la costa e interior.
\end{abstract}

Palabras claves: adopción de cerámica, residuos adheridos, vegetales cultivados, relaciones interculturales.

In the Antofagasta region, the Formative Period is defined by important socio-economic transformations related to the gradual abandonment of the hunter-gatherer way of life. Even though marine hunting and gathering continued to play a fundamental role for the arid coast inhabitants, they still experienced significant cultural changes, such as the incorporation of a foreign cooking technology. The analysis of a sample of vessels offered in coastal tumuli cemeteries (2.500-1.200 cal BP) allows us to postulate that the adoption of ceramic in the coast was related to a new culinary of cultivate vegetables, which were integrated as a supplement to the traditional marine meat diet. The incorporation of these new recipes can be seen as a collateral effect of the "formative" process lived by the inhabitants of valleys and oases from the interior desert, within a shared sociocultural construction process between people living in the coast and in the interior.

Key words: Ceramic adoption, adhered residues, cultivated vegetables, intercultural relations.

Para Willey y Phillips (1958:144), quienes sentaron las bases del período Formativo en América como alternativa al Neolítico Europeo, ciertas sociedades litorales como las de California y la Costa Noroeste norteamericana nunca calzarían en el modelo, pues aun sin agricultura ni alfarería generaron formas de organización social complejas y niveles demográficos superiores a otros pueblos formativos. James Ford (1966:782) llegaría más lejos, diciendo que el modelo es contraproducente, ya que automáticamente excluye algunas sociedades litorales.
A orillas del Océano Pacífico y a los pies del mundo Andino, la sociedad litoral del desierto de Atacama vivió de la caza y recolección marina desde el poblamiento inicial (ca.12.000 cal a.p.) hasta la llegada del mundo europeo, no sin experimentar importantes transformaciones en su organización social, estrategias políticas, niveles económicos y formas culturales a lo largo de su historia (Ballester y Clarot 2014; Llagostera 1989, 1992; Núñez 1999; Salazar et al. 2015). Una realidad social que quiebra el rígido paradigma formativo de los Andes con grupos de cazadores recolectores de baja movilidad

\footnotetext{
1 Una primera versión de este artículo fue presentada en el XIX Congreso Nacional de Arqueología Argentina, Tucumán (agosto 2016), en el marco del simposio "El tránsito de modos de vida cazadores-recolectores a agro-pastoriles en la porción meridional de los Andes Centro-Sur: Trayectorias de continuidad y cambio". Este manuscrito fue evaluado por pares externos y editado por el Comité Editorial de Chungara y los editores invitados Marcela Sepúlveda y Salomon Hocsman.

2 Departamento de Antropología, Universidad Alberto Hurtado, Santiago, Chile. kusvetiver@gmail.com

3 Los Jazmines 1386 B, depto. 103, Ñuñoa, C.P. 7780825, Santiago, Chile. carolina.carrasco.lagos@ gmail.com

4 UMR7041 ArScAN, Équipe Ethnologie Préhistorique, Université Paris 1 Panthéon-Sorbonne, Paris, Francia. benjaminballesterr@gmail.com

5 CIIR - Centro Interdisciplinario de Estudios Interculturales e Indígenas. Pontificia Universidad Católica de Chile, Santiago, Chile. fgallardo.ibanez@gmail.com
} 
residencial, cementerios monumentales colectivos, economía excedentaria y un rol protagónico en las redes regionales de circulación de bienes y productos (Ballester y Gallardo 2011; Gallardo et al. 2017; True 1975).

El proceso formativo vivido en los valles y oasis interiores repercutió a sus vecinos aun cuando no abandonaron sus formas tradicionales de subsistencia. Desde épocas arcaicas las distintas poblaciones del desierto de Atacama se encontraban vinculadas mediante lazos sociales (Ballester y Gallardo 2011; Núñez 1985; Núñez y Dillehay 1979; Núñez y Santoro 2011), compartiendo tradiciones culturales, pero también construyéndose identitariamente en función del otro, en edificaciones sostenidas por la distinción y la adopción.

En esta época una de las esferas más arraigadas de la cultura litoral, su culinaria, sufrió transformaciones debido a los cambios económicos y sociales acaecidos en valles y oasis interiores. Proceso que generó impactos socioculturales fuera de las fronteras de las incipientes poblaciones agropastoralistas, afectando la cultura de sus vecinos cazadores recolectores marinos. Estas transformaciones no fueron impuestas de una población a otra, sino posibilitadas bilateralmente en el marco de las negociaciones interculturales dentro de un proceso de intensificación de las relaciones de intercambio de bienes y conocimientos entre estos grupos, pero especialmente por la sociedad litoral para resguardar los necesarios lazos frente a otro en proceso de cambio.

Aquí estudiamos la incorporación de una tecnología de cocina foránea a la costa, la preparación de vegetales en vasijas cerámicas, artefacto que durante todo el lapso temporal del Formativo litoral (2.500-1.200 cal a.p.) no fue manufacturado en la costa, sino obtenido por intercambio con grupos interiores (Ballester y Clarot 2014; Correa et al. 2017; Gallardo et al. 2017). El estudio de una muestra de vasijas cerámicas provenientes de cementerios tumulares de Gualaguala (Mejillones) y Caleta Huelén (desembocadura del Loa) (Figura 1, Tabla 1) permitirá relevar aspectos relacionados a nuevas formas de preparación y consumo de recursos alimenticios mediante el análisis de sus huellas de uso y residuos interiores, lo que podría indicar novedosas prácticas culinarias que se integrarían de manera complementaria a la tradicional alimentación basada en proteínas marinas en este litoral.

\section{La Gente del Litoral en Tiempos Formativos}

Durante el Formativo en el litoral se gestaron importantes modificaciones en el patrón de asentamiento y cultura material. Entre los 3.0002.500 cal a.p. se quiebra el patrón dual del Arcaico Tardío que reunía espacialmente el área habitacional y funeraria, caracterizado por una arquitectura lapidaria de recintos semiaglutinados, bajo cuyos pisos estaban enterrados los fallecidos en posición extendida junto a su ajuar (Ballester y Gallardo 2011; Ballester et al. 2014; Mostny 1964; Núñez y Santoro 2011; Núñez et al. 1974).

A partir del 2.500 y hasta el 1.200 cal a.p., las poblaciones litorales construyeron los primeros cementerios de la secuencia, compuestos de tumbas individuales de forma tumular que podían llegar sobre las doscientas unidades (Figura 2). Estos constituyeron monumentos sociales inmuebles de alta visibilidad erigidos gracias a una gran inversión de trabajo colectivo (Ballester y Clarot 2014; Gallardo et al. 2017). Para cada túmulo se hacía primero una fosa cilíndrica donde se depositaba el difundo junto a su ajuar, luego desde el sedimento perimetral se levantaba el túmulo de arena y rocas en forma de volcán, dejando la cavidad central abierta, para luego cerrarla con costillas de cetáceos, troncos de cactáceas y esteras vegetales (Figura 3) (Ballester y Clarot 2014; Capdeville 1928; Gallardo et al. 2017; Moragas 1982; Mostny 1964; Núñez 1971, 1974; Spahni 1967).

Estas expresiones funerarias se distribuyen al menos desde la desembocadura del río Loa $\left(21^{\circ} 20^{\prime} \mathrm{S}\right)$ hasta el sector del Morro de Bahía Inglesa en Copiapó $\left(27^{\circ} 08^{\prime} \mathrm{S}\right)$ (Figura 1). En casi $650 \mathrm{~km}$ de litoral hemos identificado 89 cementerios tumulares $(1 / 7,3 \mathrm{~km})$ que en total suman más de 1.700 túmulos individuales (Gallardo et al. 2017). Importante inversión de trabajo colectivo centralizado en espacios funerarios monumentales que fueron dispuestos en las mismas bahías donde se emplazaban las caletas residenciales, estrategia material destinada seguramente a anclar territorialmente los espacios geográficos a sus habitantes mediante lazos filiales (antepasados) y productivos (monumentos) (Ballester y Clarot 2014; Gallardo et al. 2017).

En las tumbas se ofrendaron bienes de gran valor social, algunos provenientes de cientos de $\mathrm{km}$ producto de la inserción de los grupos litorales en extensas redes de intercambio y esferas de relaciones sociales a nivel macrorregional (Ballester y Clarot 2014; Gallardo et al. 2017). Destacan pipas, tabletas, textiles decorados, adornos de oro, collares de cuentas minerales, placas de cobre, objetos hechos con animales exóticos, restos de cultígenos y vasijas cerámicas (Ballester y Clarot 2014; Capdeville 1928; Carrasco et al. 2015; Gallardo et al. 2017; Latcham 1909; Labarca et al. 2015; Mostny 1964; Núñez 1971, 1974; Spahni 1967). Dentro del conjunto, la 

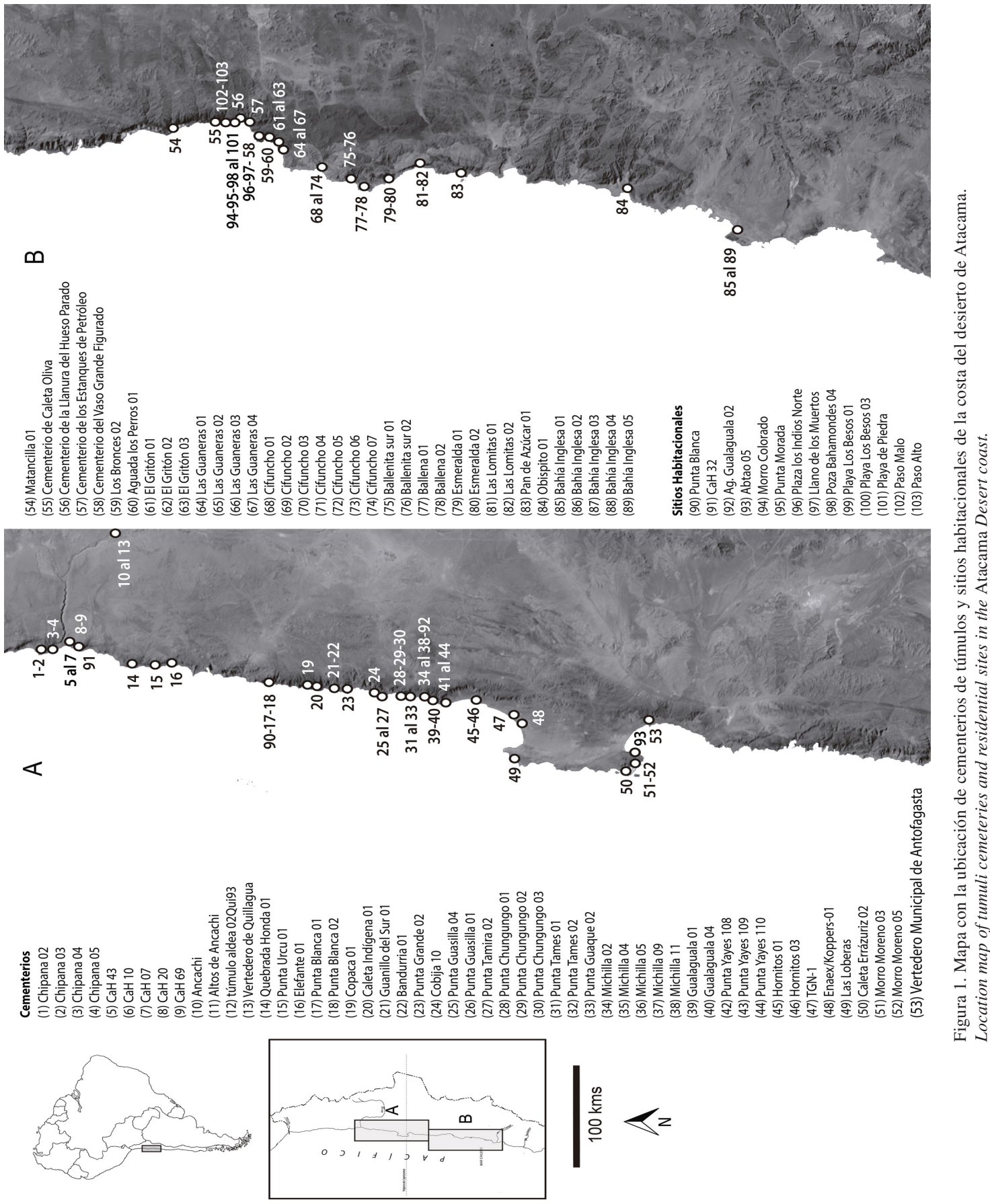
Tabla 1. Contextos y dataciones de los sitios analizados. Contexts and dating of the analyzed sites.

\begin{tabular}{|c|c|c|c|c|c|c|c|c|c|}
\hline \multirow[b]{2}{*}{ Sitio } & \multicolumn{2}{|c|}{ Detalle Cementerio } & \multicolumn{4}{|c|}{ Datación Convencional } & \multicolumn{2}{|c|}{ Datación Calibrada } & \multirow[b]{2}{*}{ Referencia } \\
\hline & $\begin{array}{c}\text { Área } \\
\left(\mathrm{m}^{2}\right)\end{array}$ & $\begin{array}{l}\text { Número } \\
\text { Unidades } \\
\text { mortuorias }\end{array}$ & $\begin{array}{c}\text { AMS } \\
\text { convencional }\end{array}$ & Material & Código & $\begin{array}{c}13 \mathrm{C} / 12 \mathrm{C} \\
(\mathrm{o} / \mathrm{oo})\end{array}$ & Cal AP (2区) & Curva & \\
\hline $\mathrm{CaH} 10$ & 6364 & 105 & $2000 \pm 70$ & Textil & IVIC 789 & - & $2062-1734$ & ShCal13.14C & Núñez 1971 \\
\hline \multirow{2}{*}{$\mathrm{CaH} 10 \mathrm{~A}$} & \multirow{2}{*}{684} & \multirow{2}{*}{-} & $1580 \pm 30$ & Vegetal & Beta 360553 & $-23,8$ & $1520-1359$ & ShCal13.14C & Gallardo et al. 2017 \\
\hline & & & $2320 \pm 80$ & Madera & IVIC-790 & - & $2494-2057$ & ShCal13.14C & Núñez 1971 \\
\hline \multirow{2}{*}{$\mathrm{CaH} 07$} & \multirow{2}{*}{690} & \multirow{2}{*}{67} & $1450 \pm 30$ & Textil & Beta 360552 & $-19,9$ & $1356-1277$ & ShCal13.14C & Gallardo et al. 2017 \\
\hline & & & $2030 \pm 80$ & Cestería & IVIC-788 & - & $2149-1743$ & ShCal13.14C & Núñez 1971 \\
\hline $\mathrm{CaH} 20$ & 7300 & 121 & $1735 \pm 100$ & $\begin{array}{l}\text { Óseo } \\
\text { Humano }\end{array}$ & HV-557 & - & - & - & Spahni 1967 \\
\hline Punta Urcu 01 & 5600 & 70 & $1930 \pm 30$ & Cordel & Beta 360559 & $-16,4$ & $1900-1739$ & ShCal13.14C & Gallardo et al. 2017 \\
\hline \multirow{2}{*}{ Michilla 02} & \multirow{2}{*}{2770} & \multirow{2}{*}{35} & $1790 \pm 30$ & Vegetal & Beta 322288 & $-19,8$ & $1727-1583$ & ShCal13.14C & Gallardo et al. 2017 \\
\hline & & & $1870 \pm 30$ & Vegetal & Beta 322287 & $-22,2$ & $1836-1701$ & ShCal13.14C & Gallardo et al. 2017 \\
\hline Michilla 04 & 544 & 5 & $2410 \pm 30$ & Calabaza & Beta 352203 & $-24,1$ & $2491-2330$ & ShCal13.14C & Gallardo et al. 2017 \\
\hline Michilla 05 & 1286 & 16 & $1160 \pm 30$ & Vegetal & Beta 352204 & $-26,8$ & $1068-0957$ & ShCal13.14C & Gallardo et al. 2017 \\
\hline \multirow{2}{*}{ Gualaguala 01} & \multirow{2}{*}{3540} & \multirow{2}{*}{26} & $1810 \pm 30$ & Vegetal & Beta 322322 & $-22,2$ & $1747-1588$ & ShCal13.14C & Gallardo et al. 2017 \\
\hline & & & $1930 \pm 30$ & Vegetal & Beta 322323 & -11.4 & $1900-1739$ & ShCal13.14C & Gallardo et al. 2017 \\
\hline \multirow{2}{*}{ Gualaguala 04} & \multirow{2}{*}{1411} & \multirow{2}{*}{18} & $1600 \pm 30$ & Vegetal & Beta 322286 & -10.8 & $1527-1374$ & ShCal13.14C & Gallardo et al. 2017 \\
\hline & & & $1830 \pm 30$ & Vegetal & Beta 322285 & -22.5 & $1752-1610$ & ShCal13.14C & Gallardo et al. 2017 \\
\hline Hornitos 01 & 6350 & 40 & $2170 \pm 30$ & $\begin{array}{l}\text { Estera } \\
\text { vegetal }\end{array}$ & Beta 352202 & -20.7 & $2161-2012$ & ShCal13.14C & Gallardo et al. 2017 \\
\hline
\end{tabular}

alfarería ha atraído la atención por su cualidad de marcador arqueológico en el advenimiento hacia el Formativo (Llagostera 1989; Núñez y Santoro 2011; Salazar et al. 2015).

Sin embargo, la frecuencia de cerámica en la mayoría de los cementerios no es alta. En $\mathrm{CaH} 20$, por ejemplo, de las 81 tumbas excavadas por Spahni (1967) solamente $45(55,56 \%)$ tenían ajuar, recuperándose 15 vasijas cerámicas en 13 entierros (una vasija/cinco tumbas). En el cementerio vecino de $\mathrm{CaH} 10$, de las 32 tumbas que excavó, solo 19 (59,38\%) contenían ajuar, con únicamente ocho piezas cerámicas (una vasija/ cuatro tumbas). Esta baja frecuencia caracteriza también los depósitos habitacionales de la misma época (Bird 1943; Castelleti 2007; Llagostera 1990). Escasa representatividad, que sumada a su uso sobrevalorado, como artefacto tipo de un período ha generado confusiones en la identificación de las ocupaciones formativas (Salazar et al. 2015). Aunque el número de investigaciones es escaso, destacan los conchales de Morro Colorado, Abtao 5 y Punta Blanca, entre tantos otros (Figura 1) (Bird 1943; Bravo 1981; Castelleti 2007; Castelleti y Maltrain 2010; Llagostera 1990; Salazar et al. 2015).
Tal como en el litoral tarapaqueño, la cerámica aparece en la costa de Antofagasta de la mano de las primeras evidencias de cultígenos (Cabello y Estévez 2017; Carrasco et al. 2015, 2017; Moragas 1977; Núñez 1974; Núñez y Moragas 1977, 1983). Hasta ahora no existen certezas de la implementación de agricultura en el litoral, pero su incipiente consumo se ve reflejado en la presencia de caries dentales en ciertos individuos enterrados en los cementerios (Andrade et al. 2016; Ardiles et al. 2011; Arias y Herrera 2012; Ballester y Clarot 2014; Clarot et al. 2014/2015; Costa y Sanhueza 1976; Santana et al. 2012). Estas relaciones no nos parecen casuales, sino consecuencia de la irrupción de una nueva culinaria complementaria de vegetales exóticos cocinados con una tecnología también foránea, la cerámica.

Los resultados de los análisis de isótopos estables de dieta de estas poblaciones litorales muestran una fuerte orientación hacia los recursos marinos de la cadena trófica más alta (Andrade et al. 2015; Ballester y Clarot 2014; Pestle, Torres-Rouff, Gallardo et al. 2015; Pestle, Torres-Rouff, Hubbe et al. 2015; Santana et al. 2012). Sin embargo, expresan también una leve diversidad alimenticia intragrupal y entre individuos distintos, por lo que no todos comieron lo mismo ni 

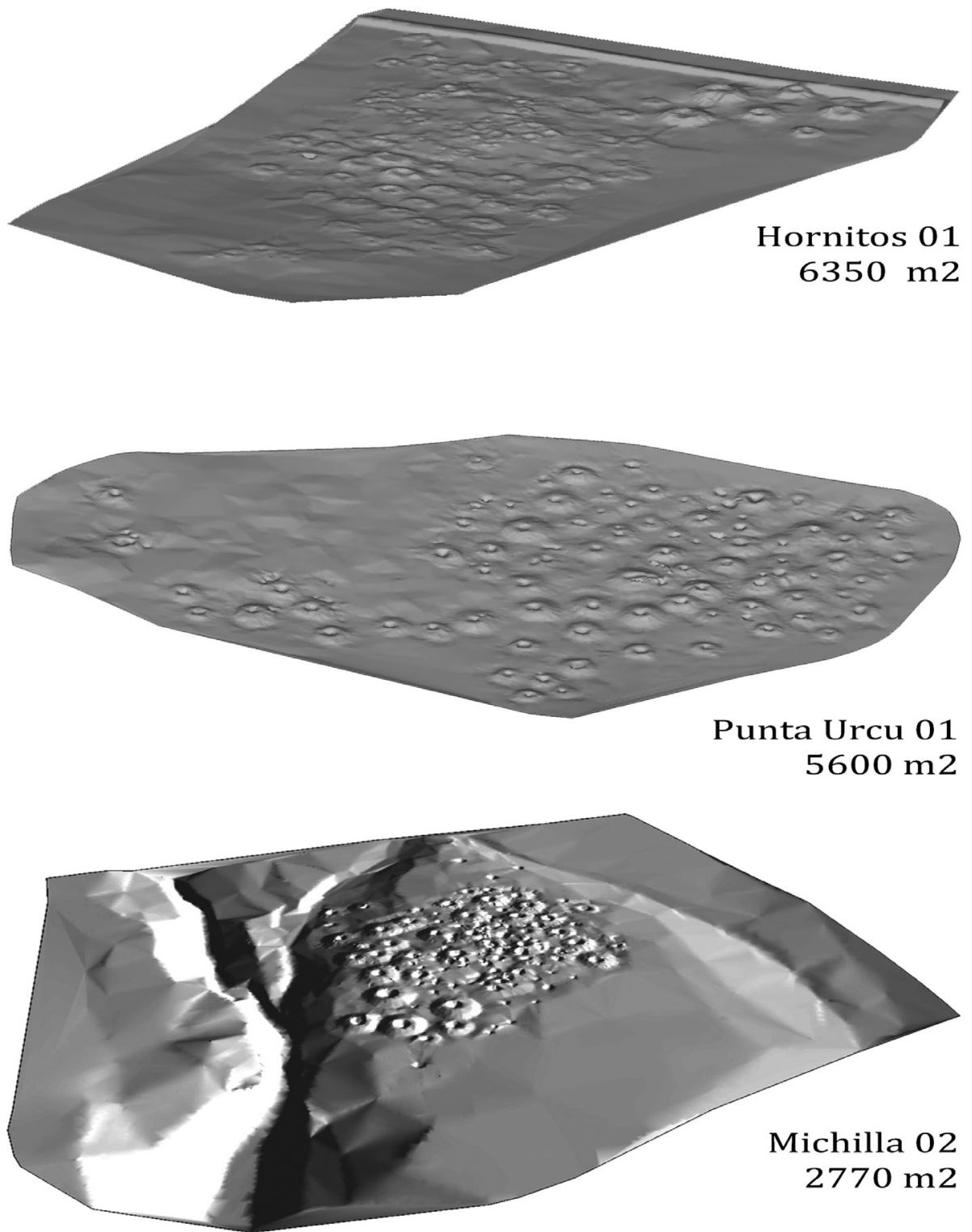

Figura 2. Representación en 3D de tres de cementerios de túmulos. Microtopografía realizada mediante un levantamiento cada $5 \mathrm{~cm}$. $3 D$ representation of three tumuli cemeteries. Microtopographic measurement every $5 \mathrm{~cm}$. 

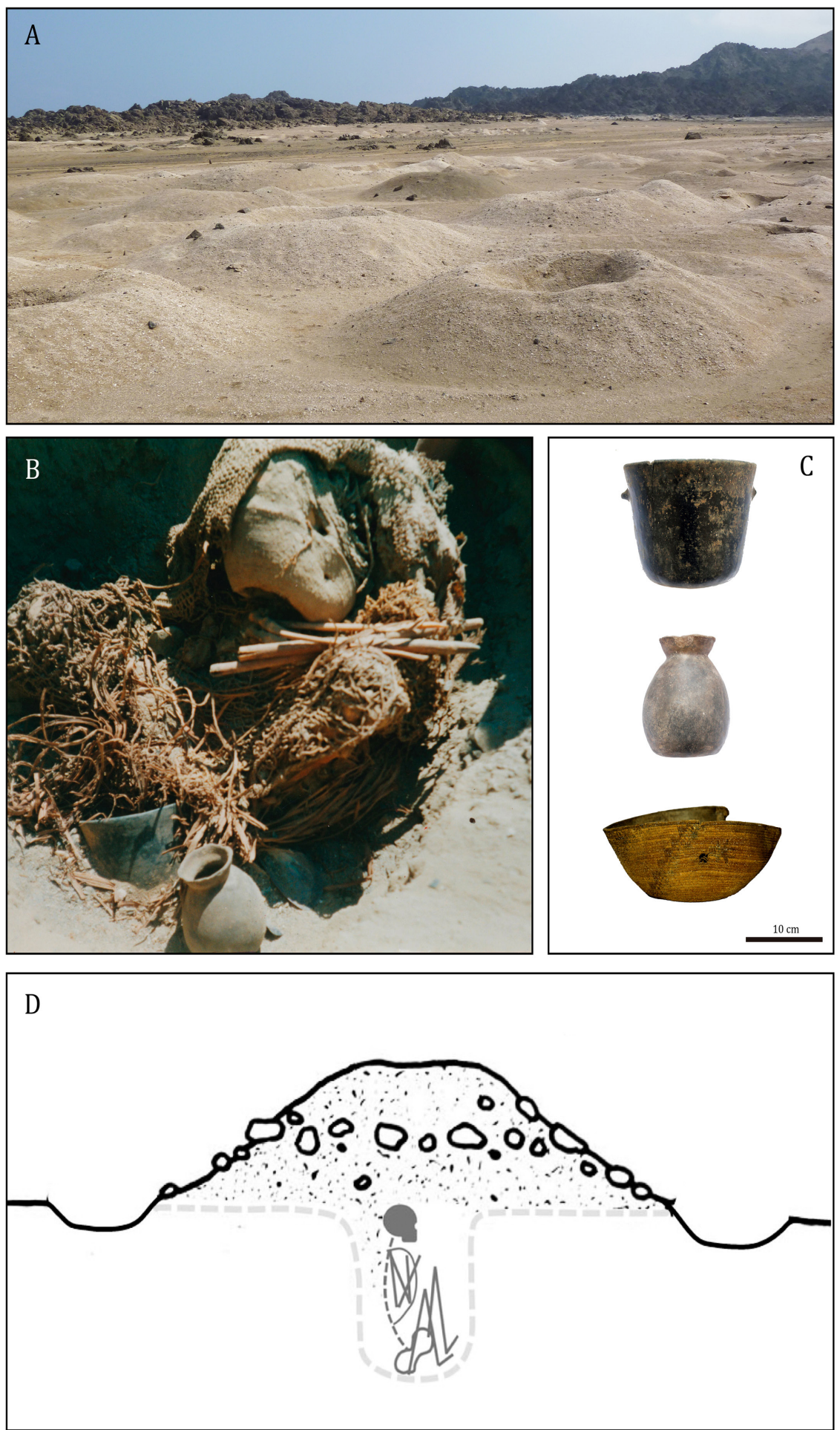

Figura 3. Detalle de los contextos tumulares de la costa del desierto de Atacama: (A) Punta Grande 02; (B) Contexto fúnebre de Las Loberas 01; (C) Vasijas cerámicas y cesto decorado de Las Loberas 01 (Ballester y Clarot 2014:102,70); (D) Esquema del corte de perfil de la arquitectura funeraria de un túmulo (modificado desde Spahni 1967:Pl.II,C). Details of the tumuli cemeteries along the Atacama Desert coast: (A) Punta Grande 02; (B) Funerary context from Las Loberas 01; (C) Ceramic vessels and decorated basket from Las Loberas 01 (Ballester and Clarot 2014:102,70); (D) Diagram of the profile cut of the funerary architecture of a tumulus (modified from Spahni 1967:Pl.II,C). 
la misma cantidad. Adicionalmente se ha probado que entre las sociedades que basan su alimentación en carnes marinas las señales de consumo de recursos vegetales en los isótopos estables tienden a invisibilizarse y ocultarse (Colonese et al. 2014), en parte debido al fenómeno de envenenamiento proteico (Noli y Avery 1988). En este sentido resulta muy probable que los grupos costeros de Antofagasta hubieran incorporado complementariamente y en baja cantidad vegetales a su cocina, sin que esto se exprese claramente en sus isótopos estables, pero si en la presencia de patologías dentales asociadas. Debido a esto se vuelve necesario correlacionar diferentes fuentes de información y argumentos analíticos, para evaluarlos de forma contextual; en este caso integrando además la evidencia cerámica, sus huellas de uso y microrrestos adheridos.

\section{El Flujo Alfarero, Bienes Foráneos para Usos Locales}

La alfarería encontrada en 21 de 31 cementerios intervenidos al norte de la Península de Mejillones fue analizada por Correa (2017) siguiendo las tipologías desarrolladas para el período en la macrorregión del norte de Chile (Tarragó 1989; Uribe 2004; Uribe y Ayala 2004). Los análisis realizados, junto con estudios complementarios de petrografía (Espinoza 2013 citado en Correa 2017) y activación neutrónica (Correa et al. 2017), entregan datos concretos sobre la procedencia foránea de la cerámica de los cementerios de túmulos, sin evidencias de producción local. Estas pesquisas indican su origen en aldeas y quebradas del desierto interior, como Guatacondo, Quillagua y San Pedro de Atacama, lo que corrobora anteriores hipótesis acerca de su origen foráneo (Ballester y Clarot 2014; Castelleti 2007; Cruz y Llagostera 2011; Salazar et al. 2015; Uribe y Ayala 2004).

La cerámica más temprana registrada en los cementerios de túmulos estudiados corresponde al tipo Loa Café Alisado (LCA) (Tabla 2, Figura 4), industria de la tradición Tarapacá que se origina en la fase temprana del período Formativo de esta región, pero que continúa manufacturándose hasta la fase tardía del período, con fechas entre ca. 2.700 y 1.400 a.p. (Uribe y Vidal 2012, 2015). Esta se encuentra presente en casi todos los cementerios de túmulos donde hemos documentado ofrendas cerámicas (Correa 2017), así como en los sitios habitacionales (Castelleti 2007). Se identifican también los tipos Quillagua Tarapacá Café Amarillento (QTC), Quillagua Rojo Pulido (QRP) y Caserones Negro Pulido (CNP) (Tabla 2, Figura 4). Preferimos referirnos a estas variedades con el nombre genérico Quillagua-Tarapacá (QT), ya que representan variaciones de una industria específica de una fase del Formativo Tardío dentro de la tradición Tarapacá
(Uribe y Vidal 2015). La cerámica QT se distribuye principalmente en la Región de Tarapacá, con fechas entre el 2.200 y el 850 a.p. (Uribe y Vidal 2012, 2015). La cerámica del componente Atacama es la menos representada en los cementerios de túmulos estudiados (Tabla 2, Figura 4). Se registra San Pedro Rojo pulido (SRP) (ca. 2.300-1.900 a.p.), tradicionalmente representativo de la fase Toconao, momento temprano del Formativo, además de San Pedro Negro Pulido (SNP) de las fases Séquitor y/o Quitorl (ca. 1.900-1.600 a.p.) (Stovel 2013; Tarragó 1989). Recientes fechas radiocarbónicas de contextos funerarios de San Pedro de Atacama desarticulan las diferencias cronológicas entre la cerámica roja y negra pulida, pudiendo ambas variedades estar en uso hasta el 1.300 a.p. (Stovel 2013).

Parte importante de los restos cerámicos rescatados en los túmulos estudiados ${ }^{2}$ mostraron evidencias de uso. Las piezas de tipo LCA, cuyas formas resultaron ser similares a las descritas en la literatura (cántaros ovoides de cuerpo amplio, de mediano a gran tamaño, golletes medianamente anchos, sin asas) (Uribe 2004; Uribe y Vidal 2012), muestran huellas de exposición al fuego, tales como hollín $(14,03 \%)$ y ahumado $(34,7 \%)$. También parte de la cerámica QT presenta evidencias de exposición al fuego, lo que se infiere del ahumado $(\mathrm{CNP}=39,5 \%, \mathrm{QRP}=5,9 \%$ y $\mathrm{QTC}=18 \%)$ y del hollín ( $\mathrm{CNP}=4,3 \%$, QRP $=2,9 \%$ y $\mathrm{QTC}=8,3 \%)$. Esta cerámica presenta una considerable variabilidad morfológica en los túmulos, desde vasijas restringidas independientes de tamaño grande, vasos "florero", cuencos campaniformes, escudillas y hasta algunas miniaturas, y las huellas de exposición al fuego no se concentran solo en una categoría de vasija particular. Para el caso de la cerámica de San Pedro, se registran vasos, cuencos y botellas correspondientes a algunos de los subtipos clásicos de esta cerámica (Correa 2017; Tarragó 1989), los cuales no muestran claras evidencias de exposición al fuego (solo 0,9\% de hollín y $1,9 \%$ de ahumado para SNP), pero sí erosión en la base y piqueteo en el borde, indicando que estuvieron sometidas a manipulación y, al igual que la cerámica LCA y QT, usadas antes de ser depositadas como ofrendas en los túmulos.

Por lo demás, algunas piezas fueron reparadas, denotando la intención de extender su vida útil luego de la fractura, registrándose orificios de reparación en prácticamente todos los tipos cerámicos y la regularización del borde mediante raspado luego de la pérdida de parte de éste o de secciones del cuello en el caso de LCA (Correa 2017) (Figura 5). La utilización de cerámica por parte de las poblaciones litorales no sólo se sustenta en la huellas de uso observada en las ofrendas fúnebres, sino que en la presencia de fragmentos de vasijas en sitios habitacionales contemporáneos (Figura 1). Adicionalmente en parte de los fragmentos se registran residuos en su interior, lo 


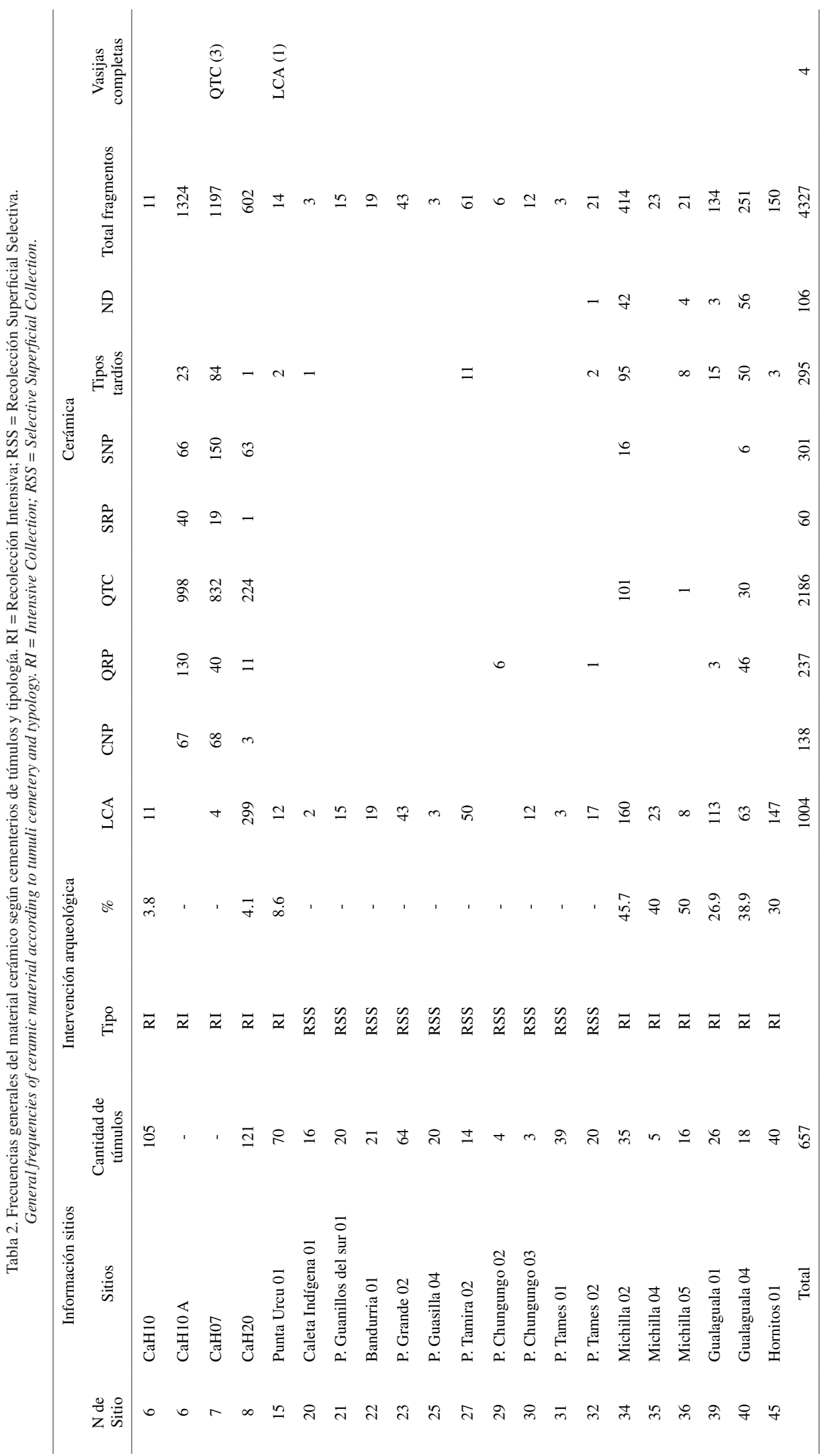



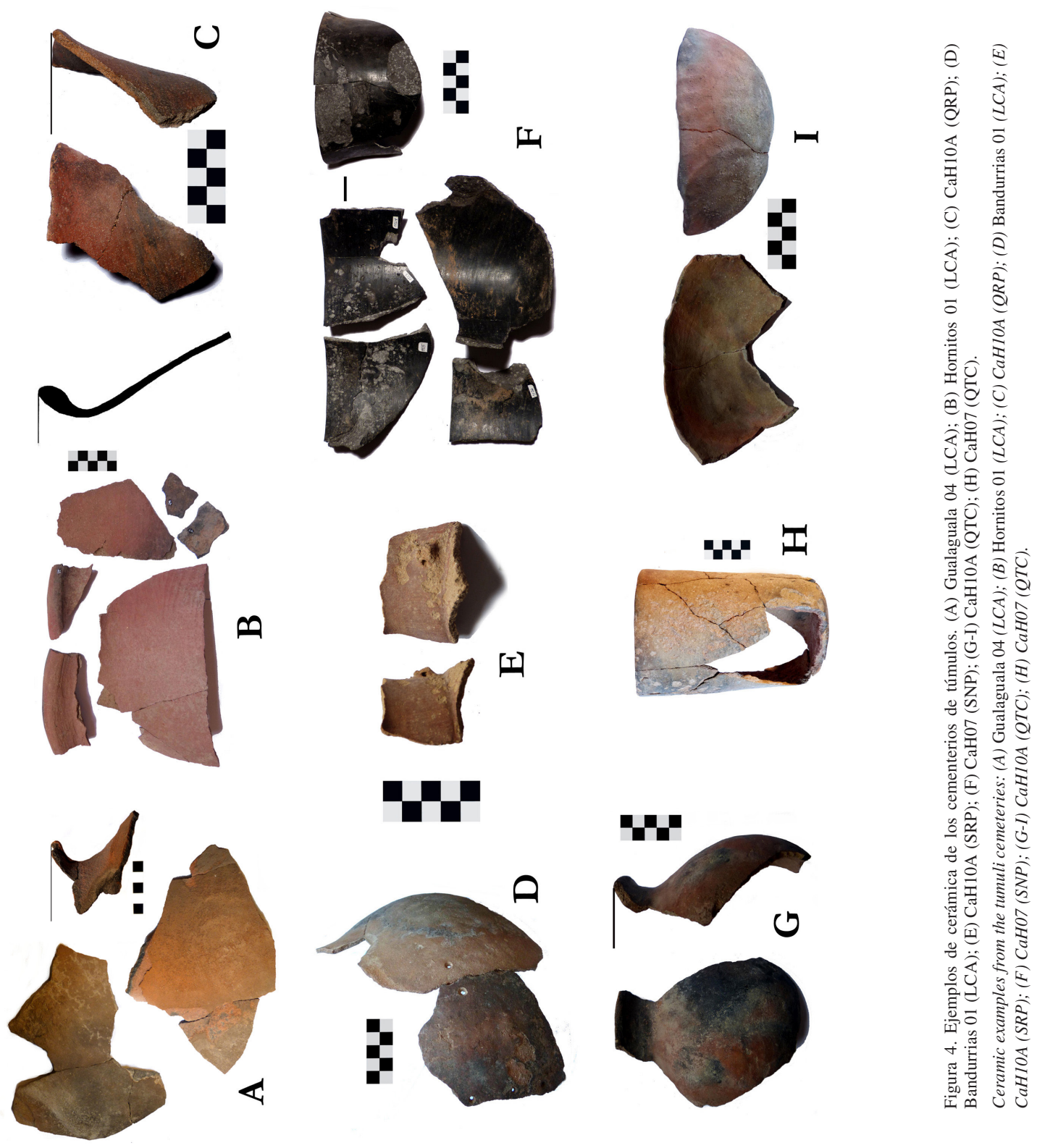

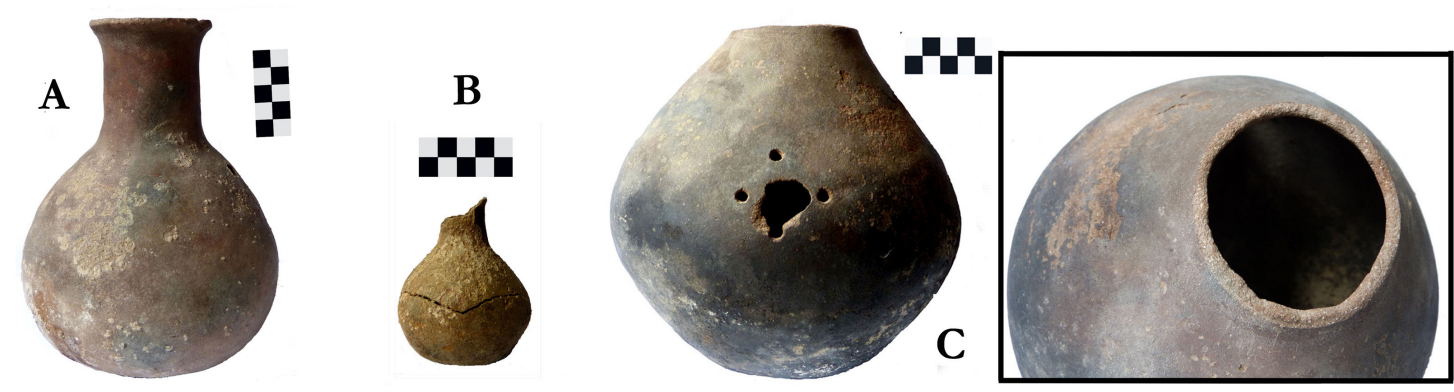

Figura 5. Vasijas completas sometidas a análisis de residuos adheridos: (A- B) CaH07, Unidad D (ofrenda a un mismo individuo) (ATC); (C) Punta Urcu 01, Túmulo 18 (LCA), detalle de regularización de borde mediante raspado.

Complete ceramic vessels submitted to adhered residues analysis (A-B) CaH07, Unit D (offering to the same individual) (ATC); (C) Punta Urcu 01, Tumuli 18 (LCA), detail of smoothing of the edge by scraping.

que constituye importante evidencia de la utilización de las vasijas.

\section{La Culinaria desde los Residuos Adheridos}

Cada vez son más los estudios de residuos adheridos en vasijas cerámicas arqueológicas (p.ej. Babot et al. 2012; Fujiwara 1982; Musaubach y Berón 2016; Pagán-Jiménez 2012; Pearsall y Piperno 1993; Petö et al. 2013; Piperno 2006; Raviele 2011; Staller y Thompson 2002), lo cual se debe a que sus resultados permiten de forma más segura definir taxones, procesamientos culturales y preparaciones (Babot et al. 2012; Musaubach 2015).

En el presente estudio trabajaremos con microfósiles vegetales, a los cuales consideramos documentos arqueológicos del uso de plantas en el pasado (cf. Wurschmidt y Korstanje 1998-1999), permitiéndonos reconocer qué alimentos se procesaron en las vasijas y constituyendo una evidencia complementaria en la corroboración de la funcionalidad de estos artefactos. Si parte importante de los recipientes cerámicos de los cementerios de túmulos estudiados muestran indicios del uso asociado a la cocción de alimentos, partimos de la premisa de que los elementos identificados se encontrarían en la esfera de lo culinario, aun considerando que cada alteración cultural de los vegetales pueda tener un origen diverso y más allá de la comida (medicinal/ritual).

Los microfósiles vegetales en su mayoría son resistentes al paso del tiempo, por lo tanto son indicadores fiables de la presencia de plantas. Para la recuperación íntegra de toda la información que nos entrega el residuo realizamos un análisis múltiple de microfósiles, visión planteada por Coil et al. (2003), que implica un muestreo poco agresivo, sin químicos, permitiendo la conservación de todo el conjunto (Korstanje 2010). Su ventaja es que si un microfósil por sí solo no nos permitiera responder a una determinación taxonómica, podemos apoyarnos en el conjunto recuperado para la identificación (Babot 2007; Coil et al. 2003).

En el universo de restos cerámicos estudiados (Tabla 2), se seleccionaron fragmentos y piezas $(n=17)$ de los tipos donde las huellas de exposición al fuego eran más frecuentes (LCA y QTC), específicamente de la zona de Gualaguala (Mejillones) y Caleta Huelén (Figuras 5 y 6), para determinar los restos vegetales que formaron parte del proceso culinario. Estos fueron seleccionados según la cantidad de residuos adheridos. Se muestrearon aquellos que presentaban diferentes coloraciones, primando el tono pardo amarillento. El residuo fue removido mediante el protocolo de raspado directo propuesto por Cueto et al. (2010).

Los utensilios de muestreo se lavaron y esterilizaron en base al protocolo de Belmar et al. (2014) para controlar la contaminación cruzada. Se observaron mediante microscopio petrográfico con cámara incorporada y sistema Metrometrics, a 250x y 400x. La descripción de forma y tipología de microfósiles (fitolitos y granos de almidón) se realizó en base a los códigos ICPN Working Group (Madella et al. 2005) e ICSN (International Code for Starch Nomenclature 2011).

La realización de colecciones de referencia y la caracterización de la flora actual, son parte importante del análisis de microfósiles. Si bien existen amplias descripciones para muchos de estos recursos (Albornoz 2015; Babot et al. 2012; Belmar et al. 2016; Kostanje y Babot 2007; Piperno 2006), realizamos colecciones propias según los recursos colectados en la costa a nivel de macrorrestos y otras variables relevantes para nuestra investigación, considerando el planteamiento multidisciplinario de "plantas útiles" (Babot 2004), donde se correlacionan evidencias etnográficas, 


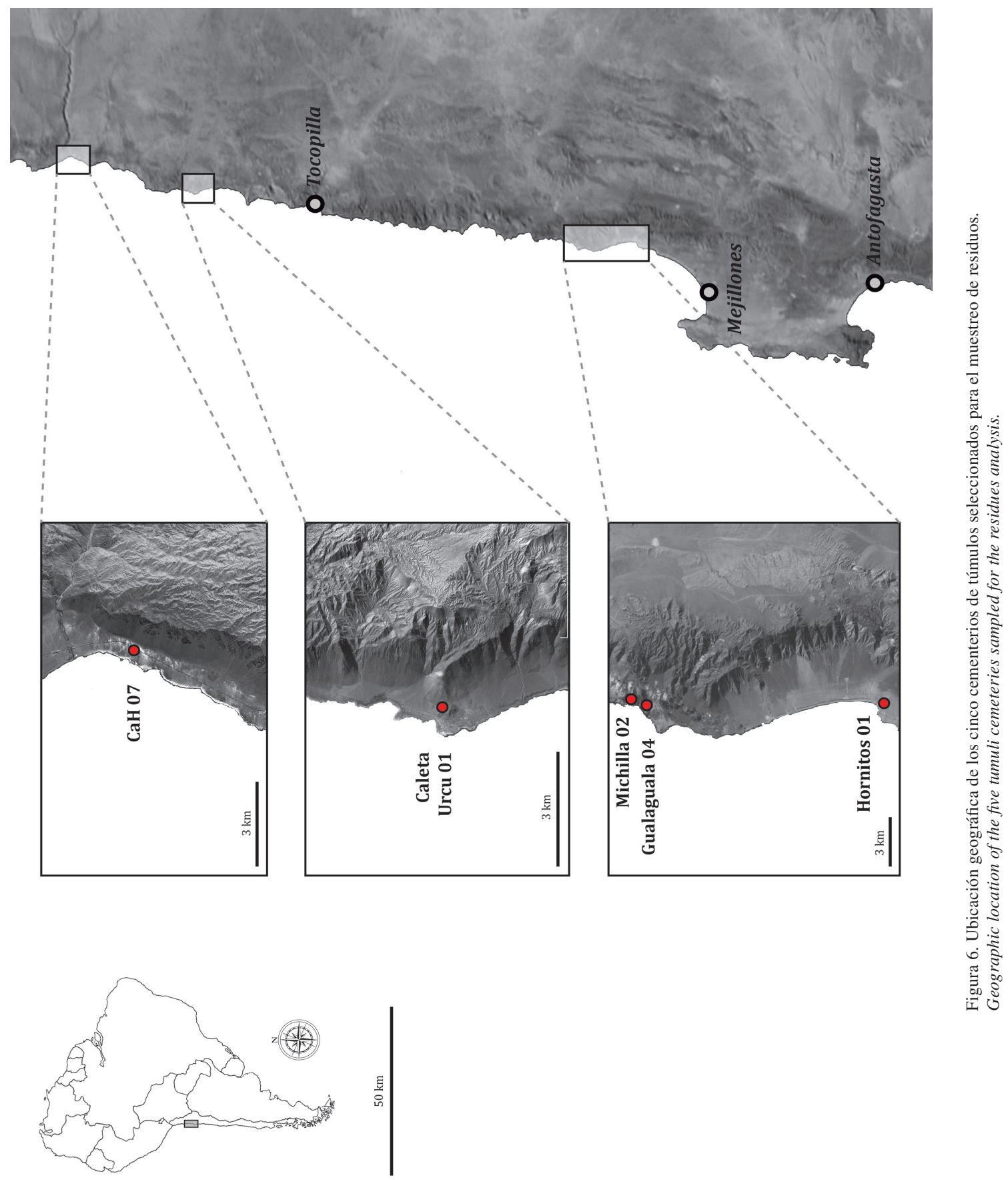


etnobotánicas, botánicas y arqueobotánicas propias de nuestra área de estudio. Adicionalmente, se complementó la información de apoyo para la identificación en base a colecciones y publicaciones relacionadas (Albornoz 2015; Babot 2003; Belmar et al. 2016; Giovannetti et al. 2008; Korstanje y Babot 2007; Piperno 2006; Planella et al. 2009).

\section{Resultados}

Se registraron 635 microfósiles, estableciéndose afinidad taxonómica de los siguientes taxones vegetales a partir de granos de almidón: Chenopodiaceae-Amaranthaceae, Chenopodium quinoa; Phaseolus spp.; cf. Phaseolus spp., cf.
Nicotiana spp. y cf. Zephyra elegans (Figura 7, Tabla 3). Dentro de este conjunto también fueron registrados calcifitolitos, esferulitas, fitolitos, diatomeas y microcarbones. Con relación a los microfósiles recuperados, los granos de almidón y fitolitos fueron los más representados, recuperándose 501 granos de almidón y 105 fitolitos del total de microrrestos (Tabla 3). Los otros microrrestos recuperados -sin adscripción taxonómica- corresponden a 29 y fueron asociados a ciertos indicadores: las diatomeas (microalgas), nos sugieren la incorporación de agua al interior de la vasija y las esferulitas como indicador de heces de mamíferos (Tabla 3), las cuales posiblemente estén relacionadas con su uso como material para combustionar ${ }^{3}$.
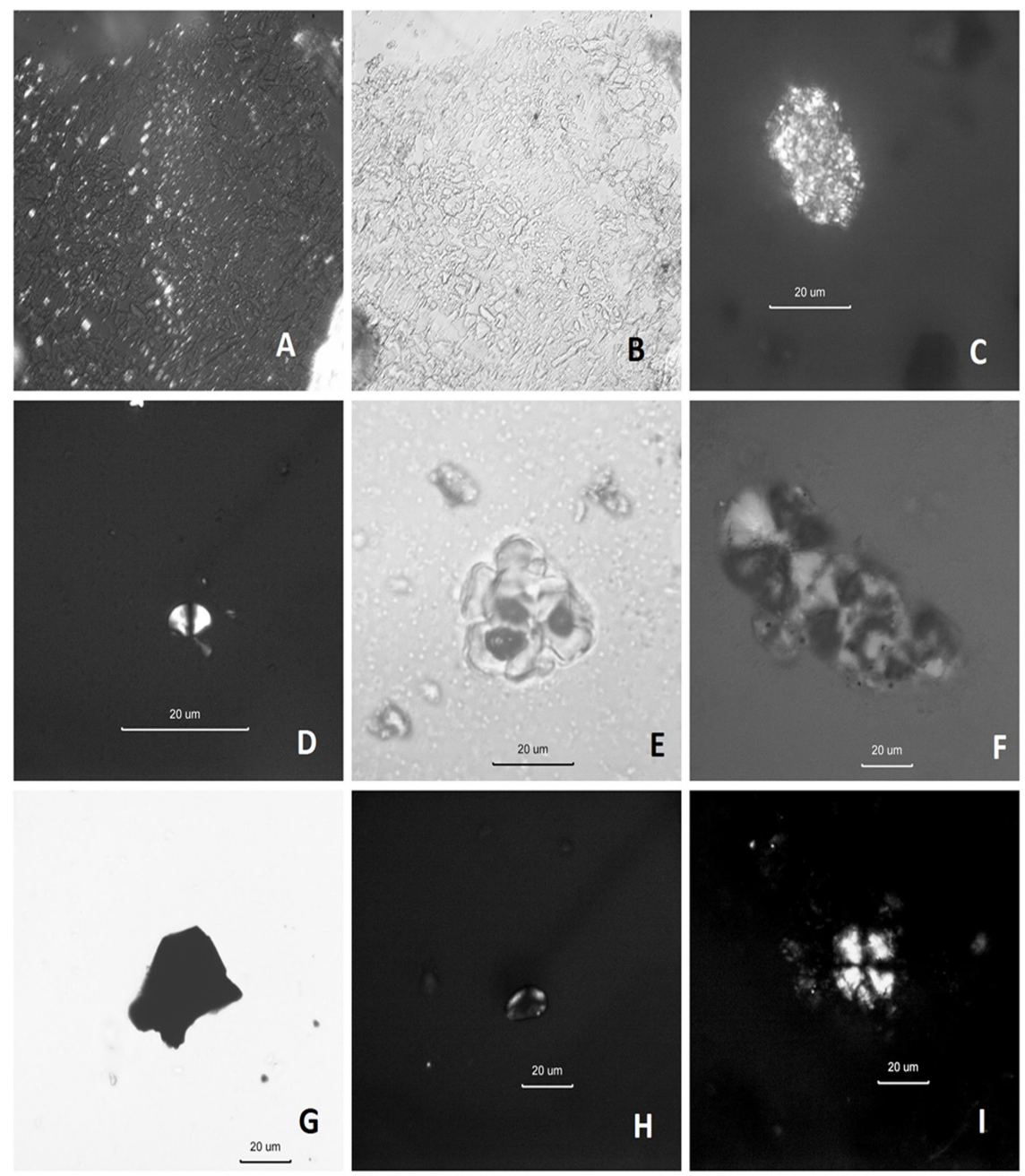

Figura 7. (A-B) Grano de almidón de Chenopodium quinoa. (C) Paquete de granos de almidón de cf. Chenopodiceae-Amaranthaceae. (D) Grano de almidón fracturado de Nicotiana sp. (E) Granos de almidón con daños por gelatinización (F) Esferulitas. (G) Microcarbón. (H) Grano de almidón de Phaseolus sp. (I) Grano de almidón de Zephyra elegans D. Don.

(A-B) Chenopodium quinoa starch grain; (C) package of cf. Chenopodiceae-Amaranthaceae starch grain; Nicotiana sp. fractured starch grain; (E) starch grains with gelatinization damage; $(F)$ Spherulites; $(G)$ Microcarbon; $(H)$ Phaseolus sp. starch grain; (I) Zephyra elegans D. Don. starch grain. 


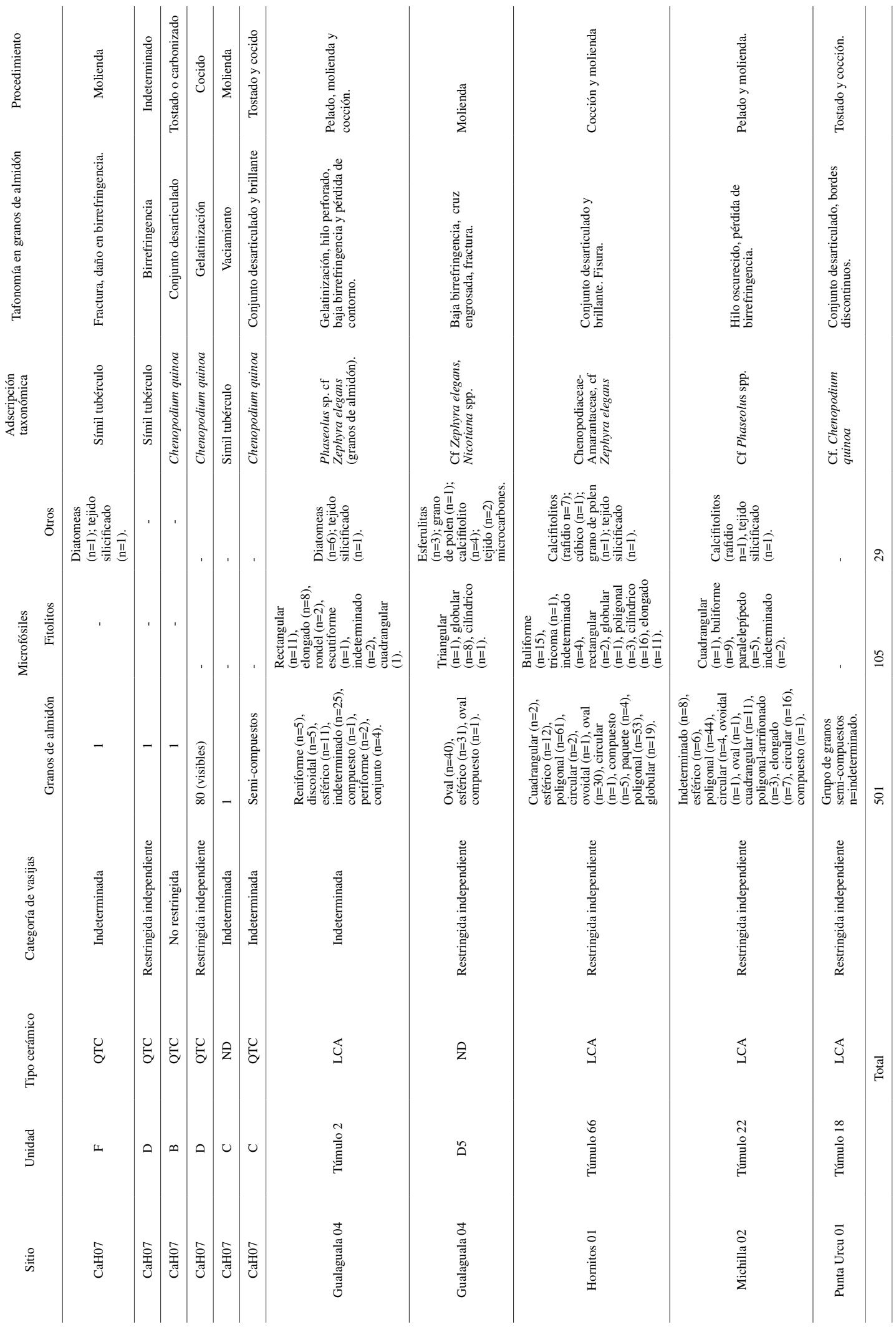


Existe una mayor representación de granos de almidón por sobre otros microfósiles, creemos que teniendo en consideración las excelentes condiciones de conservación de la costa árida de Antofagasta, el resultado puede tener relación con la selección de plantas o partes de ellas con mayor contenido energético (Babot et al. 2012). Por otra parte, la presumible presencia de tejido parenquimático de reserva y la menor frecuencia de fitolitos en el conjunto, pueden ser causa del procesamiento previo de los recursos vegetales (Babot et al. 2012), como por ejemplo, la separación de la vaina en las fabáceas o una preferencia en el uso de raíces, frutos y semillas.

Con relación a la tafonomía en la cocina (Babot 2003; Babot et al. 2014), el $100 \%$ de los granos de almidón presentó alteraciones asociadas a algún tipo de mecánica, en algunos casos perjudicando la posibilidad de identificar rasgos diagnósticos. Los otros microrrestos, no mostraron daños tafonómicos visibles. En base al trabajo experimental de Babot (2003, 2007, 2014), las alteraciones observadas en los granos de almidón son coherentes con procesamientos vinculados a prácticas culinarias como la cocción, tostado, hervido y molienda (Tabla 3). Entre los granos de almidón, se identificó un patrón de daños de tipo fractura asociados a molienda en el caso de Nicotiana spp. En Zephyra elegans la mecánica utilizada generó daños de baja birrefringencia y cruz engrosada, posiblemente asociados a la exposición a altas temperaturas. En Chenopodium quinoa se observaron alteraciones vinculadas a la gelatinización y desarticulación de los granos, esto como consecuencia del tostado y el hervido (Figura 7).

Excepcional es el registro de Nicotiana spp. ya que su uso generalmente no se asocia a la cocina, más bien está relacionado a actividades como fumar, masticar e inhalar (Guevara 1911; Wilbert 1976; Torres et al. 1991), sin embargo, se han recabado casos en los que se ha observado su consumo a modo de bebida (Serrano 1934; Wilbert 1976). Su hallazgo al interior de los contenedores analizados puede haber sido causado por su uso para contener o almacenar el vegetal, o que el vegetal formara parte de una preparación relacionada con el ámbito netamente culinario, aprovechando seguramente las cualidades farmacológicas de la planta (Gusinde 1936). Es importante agregar que la presencia de Nicotiana sp. no es extraña, en especial si consideramos que el tabaco silvestre (Nicotiana solanifolia) es un recurso de amplia distribución regional (Carrasco et al. 2015).

Es de nuestra consideración la eventualidad de que tanto las huellas de uso, como los residuos adheridos se introdujeran previo al intercambio de estos bienes, es decir, que pudieran haber sido usadas con anterioridad a su obtención por parte de los habitantes del litoral. Sin embargo, la presencia de Zephyra elegans, recurso comestible endémico del litoral (Jonhston 1930) corrobora el uso local de las vasijas. La explotación costera de este recurso ya había sido documentada con anterioridad (Moragas 1977; Núñez y Moragas 1977; Sanhueza 1985), registrándose también como ofrenda en los cementerios de túmulos de $\mathrm{CaH} 07$ y 10A, en uno de los casos dentro de una bolsa de red que contenía varias decenas del cormo (Cabello y Estévez 2017).

Al correlacionar los tipos cerámicos, las categorías morfofuncionales de las vasijas y su contenido, se vislumbran ciertas asociaciones preliminares. Los contenedores de tipo QTC muestran mayor presencia de Chenopodium quinoa y las adscritas a LCA de Phaseolus spp. (Tabla 3). Para todos los casos donde se pudo identificar la forma de la vasija, se trata de piezas restringidas independientes, lo que sugiere preparaciones en base a cocción húmeda (hervido). Recalcamos que esta inferencia es muy preliminar $y$ requiere una muestra mayor. Sin embargo, las asociaciones señaladas confirman la relación entre estos recursos y los artefactos cerámicos, ya que si bien estos vegetales foráneos han sido registrados anteriormente en contextos costeros de este mismo período (Moragas 1977; Núñez y Moragas 1977) no se había comprobado su directa vinculación con la cocción en contenedores cerámicos.

\section{Nueva Culinaria Litoral}

Uno de los aspectos clave de la adopción de vasijas cerámicas es su capacidad para la optimización nutritiva, saneamiento y ampliación del rango de los recursos potencialmente comestibles. Otro, es la mejora de la preparación de las comidas mediante cocción debido a la resistencia al fuego en comparación a otros tipos de contenedores. Sus propiedades físicas refractarias permiten soportar mayores temperaturas y alto tiempo de exposición al fuego, implicando menos cuidados durante la cocción y permitiendo al cocinero llevar a cabo otras tareas simultáneas (Arnold 1985; Atalay 2005; Beck 2009; Eerkens 2003).

En el litoral del desierto de Atacama la cerámica aparece de la mano de los primeros cultígenos, siendo ambos foráneos. Fenómeno inicialmente interpretado como evidencia de la llegada e instalación de grupos interiores a la costa, portando sus prácticas y costumbres cotidianas a un nuevo ambiente colonizado (Aldunate et al. 2010; Bravo 1981; Castro et al. 2012; Cruz y Llagostera 2011; Llagostera 1979, 1990; Núñez 1971, 1974). Sin embargo, los estudios de isótopos estables de dieta han quebrado este antiguo paradigma al demostrar que los individuos enterrados en la costa son de origen y modo de vida costeros (Andrade et al. 2015; Ballester y Clarot 2014; Pestle, 
Torres-Rouff, Gallardo et al. 2015; Pestle, TorresRouff, Hubbe et al. 2015; Santana et al. 2012), entendiéndose hoy estas poblaciones locales como agentes activos en redes de intercambios de bienes y productos a lo largo y ancho del desierto (Ballester y Gallardo 2011; Ballester y Clarot 2014; Gallardo et al. 2017; Labarca et al. 2015).

En este escenario arriba la cerámica al litoral, como parte de las redes de circulación de bienes y con vegetales cultivados. Mientras la presencia de estos últimos en la costa es menor, no deja de ser significativo, y su consumo ha podido inferirse en parte gracias a la presencia de caries (Andrade et al. 2016; Ardiles et al. 2011; Arias y Herrera 2012; Ballester y Clarot 2014; Clarot et al. 2014/2015; Costa y Sanhueza 1976; Santana et al. 2012). Nuestros resultados sobre los residuos adheridos a las vasijas cerámicas demuestran el vínculo entre contenedores y vegetales en una práctica culinaria común. La presencia de recursos costeros como Zephira elegans y Nicotiana spp., con rasgos de alternación por molienda y exposición a altas temperaturas enfatizan el uso local de la cerámica, pero además observamos la incorporación de vegetales foráneos, como quínoa, amaranto y poroto. Este último es sintomático de dicha relación, ya que para ser consumido requiere de una cocción prolongada a fin de eliminar sus microtoxinas (Arnold 1985; Jaffé 1969; Liener 1962; Morrison 2012).

La incorporación interrelacionada de estos dos productos foráneos expresa para nosotros la apertura a una nueva culinaria por parte de las poblaciones litorales a partir de este período, la que irrumpe como complemento del tradicional consumo de carnes secas y crudas que caracterizaba su modo de vida (Andrade et al. 2015, 2016; Ardiles et al. 2011; Ballester y Clarot 2014; Carrasco et al. 2017; Pestle, TorresRouff, Gallardo, Ballester y Clarot 2015; Clarot et al. 2014/2015; Pestle, Torres-Rouff, Hubbe et al. 2015; Santana et al. 2012). Como nuevo dispositivo culinario, las vasijas cerámicas aportan cambios importantes en las prácticas y recetas locales de preparación de alimentos, pues frente al consumo tradicional de carnes marinas se integran complementariamente en su recetario los vegetales hervidos y tostados. Bajo la óptica de los esquemas de oposiciones culinarias (Lévi-Strauss 1965, 1968 [1964]), surge una nueva dinámica dicotómica que materializa las relaciones costa/interior: Crudo/seco: carnes marinas : local : tradicional : hervido/tostado : vegetales cultivados : foráneo : novedoso.

Estudios de isótopos estables de dieta advierten el predominio de las proteínas marinas en su alimentación, por lo que la preparación y consumo de vegetales debió ser más bien complementaria y en baja cantidad, como elemento exótico (Andrade et al. 2015; Ballester y Clarot 2014; Pestle, Torres-Rouff,
Gallardo et al. 2015; Pestle, Torres-Rouff, Hubbe et al. 2015; Santana et al. 2012). Sin embargo, por reducida que fuera la ingesta de estos alimentos, la incorporación de la cocción de vegetales en vasijas cerámicas constituye una notable transformación de la culinaria y mesa litoral, lo que necesariamente conlleva modificaciones culturales importantes, seguramente como respuesta a los cambios socioeconómicos acaecidos entre las poblaciones de valles y oasis.

\section{Conclusiones: Impactos Socioculturales y Efectos Colaterales}

Ya desde la formulación del período Formativo en la década de 1950 ciertas sociedades litorales quedaron fuera del modelo (Willey y Phillips 1958). Críticas locales posteriores continuaron enfatizando estas incongruencias, propias de una generalización que invisibiliza los diversos procesos de complejización social regionales (Lumbreras 2006). Se hace evidente que el modelo clasificatorio de periodificación debe variar, integrando las múltiples realidades y valorando sus procesos históricos.

El Formativo de la región de Antofagasta ha sido concebido como un proceso de complejización social que deja paulatinamente atrás el modo de vida cazador-recolector, expresado en la sedentarización, producción excedentaria de alimentos (agricultura y ganadería), arquitectura pública y privada, y la expansión de las redes de intercambio, junto a innovaciones tecnológicas artesanales como la alfarería, metalurgia y textilería (Agüero 2005; Agüero et al. 2006; Castro et al. 2016; Sinclaire 2004). En el litoral las innovaciones se expresaron en distintos ritmos y momentos, pues ya desde el Arcaico Tardío (6.500-4.000 cal a.p.) se registran asentamientos con arquitectura lapidaria formal de carácter comunal, espacios funerarios colectivos, generación de excedentes y la inserción en esferas macrorregionales de relaciones sociales, expresada en el flujo de bienes, personas e ideas (Ballester y Gallardo 2011; Ballester et al. 2014; Núñez y Santoro 2011; Núñez et al. 1974). La escisión del ámbito doméstico del fúnebre no aparece aquí, sino milenios después hacia los 2.500 cal a.p., dando inicio a los cementerios tumulares (Ballester y Clarot 2014; Bittmann 1984; Gallardo et al. 2017; Spahni 1967). Es así como solo en esta época irrumpe el consumo de alfarería y vegetales cultivados, desligados de su manufactura y producción, y asociados a reacomodos culturales de la culinaria litoral. Situación que interpretamos como un efecto colateral de los cambios que vivían sus vecinos de valles y oasis interiores, en el marco de sus relaciones y negociaciones interculturales.

Resulta por tanto evidente que las comunidades litorales experimentaron un proceso de transformaciones históricas diferentes a las observadas en el interior de la 
región, pero enmarcadas en las redes de intercambio costa-interior. Si estos sistemas favorecieron consensos culturales a escala regional (Castro et al. 2016), no es de extrañar el importante papel de una nueva culinaria derivada de estas dinámicas interculturales. La incorporación complementaria de cerámica en el litoral, en asociación a vegetales cultivados, sería el resultado de factores relacionales, donde la importancia de la adopción de nuevas prácticas recae en la referencia al otro (Hoopes 1995) en un proceso de construcción social, cultural, político y económico compartido. Nos parece que aquí la integración cultural queda manifiesta no solo en la integración de un paquete culinario foráneo completo en la mesa litoral -vegetales cultivados cocidos en vasijas cerámicas-, sino también en nuevos modos de preparación de los recursos locales, como sucede con Zephira elegans, vegetal antes consumido en la costa sin preparación alguna y ahora cocida en vasijas cerámicas.

Agradecimientos: Proyecto FONDECYT 1160045. A Francisca Santana por la colaboración. Consejo de Monumentos Nacionales Órdenes $\mathrm{N}^{\circ} 2250 / 12$ del 30 de mayo de 2012 y $\mathrm{N}^{\circ} 000177 / 13$ del 15 de enero de 2013. A Salomón Hocsman y Marcela Sepúlveda, coordinadores del simposio. A los evaluadores por sus aportes críticos.

\section{Referencias Citadas}

Agüero, C. 2005. Aproximación al asentamiento humano temprano en los oasis de San Pedro de Atacama. Estudios Atacameños 30:29-60.

Agüero, C., P. Ayala, M. Uribe, C. Carrasco y B. Cases 2006. El período Formativo desde Quillagua, Loa Inferior. En Esferas de Interacción Prehistóricas y Fronteras Nacionales Modernas: Los Andes Sur Centrales, editado por H. Lechtman, pp.73-125. Instituto de Estudios Peruanos, Lima.

Albornoz, X. 2015. Colección de referencia de elementos histológicos para estudios de microrrestos vegetales. Especies psicoactivas y aromáticas de los Andes Centro-Sur. En Avances y Desafíos Metodológicos en Arqueobotánica. Miradas Consensuadas y Diálogos Compartidos desde Sudamérica, editado por C. Belmar y V. Lema, pp.497-516. Ediciones Universidad SEK, Santiago.

Aldunate, C., V. Castro y V. Varela 2010. Los atacamas y el pescado de Cobija. En homenaje al maestro John Víctor Murra. Chungara Revista de Antropología Chilena 42:341-347.

Andrade, P., V. Castro y C. Aldunate 2016. Reconstrucción del modo de vida de individuos del arcaico de la costa arreica del norte de Chile: una aproximación bioarqueológica desde el sitio Copaca 1. Chungara Revista de Antropología Chilena 48:73-90.

Andrade, P., R. Fernández, K. Codjambassis, J. Urrea, L. Olguín, S. Rebolledo, F. Lira, C. Aravena y M. Berrios 2015. Subsistence continuity linked to consumption of marine protein in the Formative Period in the interfluvic coast of northern Chile: reassessing contacts with agropastoral groups from highlands. Radiocarbon 57:1-10.

Ardiles, H., B. Ballester y A. Clarot 2011. Elección de dieta en poblaciones pasadas costeras de la II región: una mirada multidisciplinaria. Informes FAIP 14:83-110.

Arias, M. y M. Herrera 2012. Caracterización del modo de vida, salud y dieta de las poblaciones de los cementerios Caserones-Tarapacá 40 y Cáñamo 3 (Período Formativo, Región de Tarapacá). Actas del XVIII Congreso Nacional de Arqueología Chilena, pp. 53-62. Sociedad Chilena de Arqueología, Santiago.
Arnold, D. 1985. Ceramic Theory and Cultural Process. Cambridge University Press, Cambridge.

Atalay, S. 2005. Domesticating clay: the role of clay balls, mini balls and geometric objects in daily life at Çatalhöyük. Changing Materialities at Çatalhöyük: Reports from the 1995-99 Seasons, editado por I. Hodder, pp. 139-168. Çatalhöyük Project Volume 5, McDonald Institute for Archaeological Research/British Institute of Archaeology at Ankara, Cambridge.

Babot, M. 2003. Starch grain damage as an indicator of food processing. En Phytolith and Starch Research in the Australian- Pacific -Asian Regions: The State of the Art, editado por D. Hart y L. Wallis, pp.69-81. Pandamus Books for the Centre for Archaeological Research, Canberra.

Babot, M. 2004. Tecnología y Utilización de Artefactos de Molienda en el Noroeste Prehispánico. Tesis Doctoral, Facultad de Ciencias Naturales e IML, Universidad Nacional de Tucumán, Tucumán.

Babot, M., S. Hocsman, R. Piccón y M. Haros 2012. Recetarios prehispánicos y tradiciones culinarias. Casos de la Puna Argentina. En Las Manos en la Masa. Arqueologías, Antropologías e Historias de la Alimentación en Suramérica, editado por M. Babot, M. Marschoff y F. Pazzarelli, pp. 235269. Universidad Nacional de Córdoba, Córdoba.

Babot, M., J. Lund y V. Olmos 2014. Taphonomy in the kitchen: culinary practices and processing residues of native tuberous plants of the South-Central Andes. Intersecciones en Antropología Volumen especial 1:35-54.

Ballester, B. y F. Gallardo 2011. Prehistoric and historic networks on the Atacama Desert coast (northern Chile). Antiquity 85:875-889.

Ballester, B. y A. Clarot 2014. La Gente de los Túmulos de Tierra. Marmot Impresores, Santiago.

Ballester, B., A. Clarot, V. Bustos, A. Llagostera y H. Garcés 2014. Arqueología de la prehistoria de la Península de Mejillones: el campamento de Los Canastos 3 desde sus cuadernos de campo y materiales de museo. Boletín de la Sociedad Chilena de Arqueología 43/44:5-21. 
Beck, M. 2009. Residential mobility and ceramic exchange: Ethnography and archaeological implications. Journal of Archaeological Method and Theory 16:320-356.

Belmar, C., X. Albornoz, S. Alfaro, F. Meneses, C. Carrasco, L. Quiroz, M. Babot y M. Planella 2016. Reconstruyendo las prácticas fumatorias del sitio La Granja (130 a 1000 d.C., Valle del Río Cachapoal, VI Región, Chile Central) a partir de los microfósiles. Chungara Revista de Antropología Chilena 48:53-72.

Belmar, C., L. Quiroz, H. Niemeyer, M. Planella, X. Albornoz, F. Meneses, S. Alfaro, C. Carrasco, K. Collao-Alvarado y J. Echeverría 2014. Condiciones para el uso de marcadores arqueobotánicos y químicos en estudios arqueológicos y arqueométricos sobre complejos fumatorios. Intersecciones en Antropología 15:497-501.

Bird, J. 1943. Excavations in northern Chile. Anthropological Papers of the American Museum of Natural History 38(4):173318.

Bittmann, B. 1984. El Proyecto Cobija: investigaciones antropológicas en la costa del Desierto de Atacama. En $44^{\circ}$ Congreso Internacional de Americanistas, Simposio Culturas Atacameñas, pp. 99-146. Manchester.

Bravo, L. 1981. Abtao-5: Un Modelo de Adaptación Tardía a la Costa de la Segunda Región. Memoria para optar al título de Arqueólogo, Universidad del Norte, Antofagasta.

Cabello, G. y D. Estévez 2017. No sólo de peces vive el hombre: vegetales en la costa durante el período Formativo. En Monumentos Funerarios de la costa del Desierto de Atacama: Contribuciones al Intercambio de Bienes $e$ Información entre Cazadores-Recolectores Marinos (Norte de Chile), editado por F. Gallardo, B. Ballester y N. Fuenzalida. CIIR-SCHA, Santiago, en prensa.

Capdeville, A. 1928. Como descubrí la industria paleolítica americana de los sílices negros tallado en la zona de la costa de Taltal. Revista Chilena de Historia Natural 32:348-364.

Carrasco, C., I. Correa, C. Belmar, B. Ballester y F. Gallardo 2017. Cocinando relaciones interculturales: residuos adheridos en vasijas cerámicas de grupos cazadores recolectores marinos del desierto de Atacama (Período Formativo, norte de Chile). Estudios Atacameños, http://dx.doi.org/10.4067/ S0718-10432017005000009.

Carrasco, C., J. Echeverría, B. Ballester y H. Niemeyer 2015. De pipas y sustancias: costumbres fumatorias durante el período Formativo en el litoral del Desierto de Atacama (Norte de Chile). Latin American Antiquity 26:143-163.

Castelleti, J. 2007. Patrón de Asentamiento y Uso de Recursos a Través de la Secuencia Ocupacional Prehispánica en la Costa de Taltal. Tesis para optar al grado de Magister en Arqueología, Universidad Católica del Norte, Antofagasta.

Castelleti, J. y G. Maltrain 2010. El formativo de Taltal y el patrón de asentamiento local. Actas del XVII Congreso Nacional de Arqueología Chilena, Tomo 1, pp. 165-176. Ediciones Kultrún, Valdivia.

Castro, V., C. Aldunate y V. Varela 2012. Paisajes Culturales de Cobija, Costa de Antofagasta, Chile. Revista de Antropología 26:97-128.

Castro, V., J. Berenguer, F. Gallardo, A. Llagostera y D. Salazar 2016. Vertiente occidental circumpuneña. Desde las sociedades posarcaicas hasta las preincas (ca. 1.500 años
a.C. a 1.470 años d.C.). En Prehistoria en Chile. Desde sus Primeros Habitantes hasta los Incas, editado por F. Falabella, M. Uribe, L. Sanhueza, C. Aldunate y J. Hidalgo, pp.239283. Editorial Universitaria, Santiago.

Clarot, A., A. Méndez y B. Ballester 2014/2015. Un costeño del Desierto de Atacama: acercamiento al modo de vida en el Periodo Intermedio Tardío mediante imagenología e isótopos estables. Taltalia 7/8:39-60.

Coil, J., A. Korstanje, S. Archer y C. Harstof 2003. Laboratory goals and considerations for multiple microfossil extraction in archaeology. Journal of Archaeological Science 30:991-1008.

Colonese, A., M. Collins, A. Lucquin, M. Eustace, Y. Hancock, R. de Almeida, A. Mora, C. Smith, P. DeBlasis L. Figuti, V. Wesoloski, C. Plens, S. Eggers, D. Scunderlick, A. Gledhill y O. Edward 2014. Long-Term Resilience of Late Holocene Coastal Subsistence System in Southeastern South America. PLoS ONE 9:e93854. doi:10.1371/journal.pone.0093854

Correa, I. 2017. La cerámica de los túmulos costeros de la región de Antofagasta: Ofrendas funerarias, intercambio y nuevas prácticas culinarias, Período Formativo Medio (500 a.C 100 d.C.) y Formativo Tardío (100-700 d.C.). En Monumentos Funerarios de la Costa del Desierto de Atacama: Contribuciones al Intercambio de Bienes e Información entre CazadoresRecolectores Marinos (Norte de Chile), editado por F. Gallardo, B. Ballester y N. Fuenzalida. CIIR-SCHA, Santiago, en prensa.

Correa, I., F. Gallardo, M. Uribe, E. Echenique, J. Blanco, S. Flewett, M. Boulanger y M. Glascock 2017. Pottery from funerary mounds along the arid Atacama Desert coast, Chile: Chemistry, circulation, and exchange between the inlands and coast during the Formative Period. En Ceramics of the Indigenous Cultures of South America: Studies of Production and Exchange, editado por M. Glascock, H. Neff y K. Vaughn. University of New Mexico Press, New Mexico, en prensa.

Costa, M. y J. Sanhueza 1976. Poblaciones Precolombinas de la Costa Norte de Chile: Restos Óseos Humanos de los Cementerios Punta Blanca y Auto Club (Antofagasta). Seminario Medio Integral. Depto. Ciencias Sociales. Universidad del Norte, Antofagasta.

Cruz, J. y A. Llagostera 2011. Prehistoria de Antofagasta. En la Ruta de los Primeros Antofagastinos. Morgan Impresores, Antofagasta.

Eerkens, J.W. 2003. Residential mobility and pottery use in the Western Great Basin. Current Anthropology 44:728-737.

Ford, J. 1966. Early formative cultures in Georgia and Florida. American Antiquity 31:781-799.

Gallardo, F., B. Ballester y N. Fuenzalida (eds.) 2017. Monumentos Funerarios de la Costa del Desierto de Atacama: Contribuciones al Intercambio de Bienes $e$ Información entre Cazadores-Recolectores Marinos (Norte de Chile). CIIR-SCHA, Santiago, en prensa.

Giovannetti, M., A. Capparelli y M. Pochetino 2008. La Arqueobotánica en Sudamérica. ¿Hacia un equilibrio de enfoques? Discusión en torno a las categorías clasificatorias y la práctica arqueobotánica y paleoetnobotánica. En Arqueobotánica y Teoría Arqueológica: Discusiones desde Suramérica, editado por S. Archilla, M. Giovannetti y V. Lema, pp.17-34. Universidad de Los Andes, Bogotá.

Guevara, T. 1911. Folklore Araucano: Refranes, Cuentos, Cantos, Procedimientos Industriales, Costumbres Pre-hispanas. Imprenta Cervantes, Santiago. 
Gusinde, M. 1936. Plantas medicinales que los indios araucanos recomiendan. Anthropos 31:850-873.

Hoopes, J. 1995. Interaction in hunting and gathering societies as a context for the emergence of pottery in the Central American Isthmus. En The Emergence of Pottery: Technology and Innovation in Ancient Societies, editado por W. Barnett y J. Hoopes, pp.185-198. Smithsonian Institution Press, Washington D.C.

Jaffé, W. 1969. Hemagglutinins. En Toxic Constituents of Plant Foodstuffs, editado por I. Liener, pp.69-101. Academic Press, New York.

Jonhston, I. 1930. Some notes on the flora of northern Chile. Revista Chilena de Historia Natural 34:228-234.

Korstanje, M. 2010. Producción y consumo agrícola en el Valle del Bolsón (1992-2005). En Arqueología de la Agricultura: Casos de Estudio en la Región Andina Argentina, editado por M. Korstanje y M. Quesada, pp.48-75. Magna, Tucumán.

Korstanje, M. y M. Babot 2007. A microfossil characterization from South Andean economic plants. En Plants, People and Places: Recent Studies in Phytholithic Analysis, editado por M. Madela y D. Zurro, pp.41-72. Oxbow Books, Cambridge.

Labarca, R., E. Calás, F. Gallardo, B. Ballester y A. Prieto 2015. Chaetophractus vellerosus Gray 1865 (Xenarthra, Dasypodidae) en un cementerio de túmulos de la desembocadura del río Loa (Región de Antofagasta, Chile): evidencias de conexiones con el altiplano andino, Periodo Formativo Tardío (300 a.C-500 d.C.). Estudios Atacameños 50:47-58.

Latcham, R. 1909. El comercio precolombino en Chile y otros países de América. Anales de la Universidad de Chile 125:241-284.

Lévi-Strauss, C. 1965. Le triangle culinaire. L'Arc 26:19-29.

Lévi-Strauss, C. 1968 [1964]. Mitológicas I: Lo Crudo y lo Cocido. Fondo de Cultura Económica, México D.F.

Liener, I. 1962. Toxic factors in edible legumes and their elimination. American Journal of Clinical Nutrition 11:281298.

Llagostera, A. 1979. 9700 years of maritime subsistence on the pacific: an analysis by means of bioindicators in the North of Chile. American Antiquity 44:309-324.

Llagostera, A. 1989. Caza y pesca marítima (9.000 a 1.000 a.C.). En Culturas de Chile. Prehistoria: Desde sus Orígenes hasta los Albores de la Conquista, editado por J. Hidalgo, V. Schiappacasse, H. Niemeyer, C. Aldunate e I. Solimano, pp.57-79. Editorial Andrés Bello, Santiago.

Llagostera, A. 1990. La navegación prehispánica en el Norte de Chile: bioindicadores e inferencias teóricas. Chungara 24/25:37-51.

Llagostera, A. 1992. Early occupations and the emergence of fishermen on the Pacific Coast of South America. Andean Past 3:87-109.

Lumbreras, L. 2006. Un Formativo sin cerámica y cerámica preformativa. Estudios Atacameños 32:11-34.

Moragas, C. 1977. Continuidad y Cambio Socio-Económico en una Ocupación del Litoral Desértico. DistritoArqueológico de Cáñamo (Norte de Chile, I Región). Memoria para optar al título de Arqueóloga, Universidad del Norte, Antofagasta.
Moragas, C. 1982. Túmulos funerarios de la costa sur de Tocopilla (Cobija), II Región. Chungara 9:152-173.

Morrison, K. 2012. Great transformations: On the archaeology of cooking. En The Menial Art of cooking. Archaeological studies of cooking and food Preparation, editado por S. Graff y E. Rodríguez, pp. 231-244. University Press of Colorado, Boulder.

Mostny, G. 1964. Arqueología de Taltal: Epistolario de Augusto Capdeville con Max Uhle y Otros. Fondo Histórico y Bibliográfico José Toribio Medina, Santiago.

Musaubach, M. 2015. Microrrestos vegetales en contenidos cerámicos. Análisis arqueobotánicos en un contexto de cazadores recolectores de la pampa occidental. En Avances y Desafíos Metodológicos en Arqueobotánica. Miradas Consensuadas y Diálogos Compartidos desde Sudamérica, editado por C. Belmar y V. Lema, pp.497-516. Universidad SEK, Santiago.

Musaubach, M. y M. Berón 2016. Food residues as indicators of processed plants in hunter-gatherers'pottery from La Pampa (Argentina). Vegetation History an Archaeobotany 26:111-123.

Noli, D. y G. Avery 1988. Protein poisoning and coastal subsistence. Journal of Archaeological Science 15:395-401.

Núñez, L. 1971. Secuencia y cambio en los asentamientos humanos de la desembocadura del Río Loa, en el Norte de Chile. Boletín de la Universidad de Chile 112:2-25.

Núñez, L. 1974. La Agricultura Prehistórica en los Andes Meridionales. Editorial Orbe, Santiago.

Núñez, L. 1985. Tráfico de Complementariedad de Recursos entre las Tierras Altas y el Pacífico en el Área Centro-Sur Andina. Tesis doctoral, Universidad de Tokio, Tokio.

Núñez, L. 1999. Archaic adaptation on the South-Central Andean coast. En Pacific Latin American in Prehistory. The Evolution of Archaic and Formative Cultures, editado por M. Blake, pp.199-211. Washington State University Press, Washington D.C.

Núñez, L. y T. Dillehay 1979. Movilidad Giratoria, Armonía social y Desarrollo en los Andes Meridionales: Patrones de Tráfico e Interacción Económica. Ensayo. Universidad Católica del Norte, Antofagasta.

Núñez, L. y C. Moragas 1977. Una ocupación con cerámica temprana en la secuencia del distrito de Cáñamo (costa desértica del norte de Chile). Estudios Atacameños 5:23-50.

Núñez, L. y C. Moragas 1983. La cerámica temprana de Cáñamo (Costa desértica del norte de Chile): análisis y evaluación regional. Chungara 11:31-61.

Núñez, L. y C. Santoro 2011. El tránsito arcaicoformativo en la circumpuna y valles occidentales del centro sur andino: hacia los cambios "neolíticos". Chungara Revista de Antropología Chilena 43:487-530.

Núñez, L., V. Zlatar y P. Núñez 1974. Caleta Huelén 42: una aldea temprana en el norte de Chile (nota preliminar). Hombre y Cultura 2(5):67-103.

Pestle, W., C. Torres-Rouff, F. Gallardo, B. Ballester y A. Clarot 2015. Mobility and exchange among marine hunter-gatherer and agropastoralist communities in the Formative Period Atacama Desert. Current Anthropology 15:121-133. 
Pestle, W., C. Torres-Rouff, M. Hubbe, F. Santana, G. Pimentel, F. Gallardo y K. Knudson 2015. Explorando la diversidad dietética en la prehistoria del Desierto de Atacama: Un Acercamiento a los Patrones Regionales. Chungara Revista de Antropología Chilena 47:201-209.

Petö, Á., F. Gyulai, D. Pópity y Á. Kénez 2013. Macro and micro archaeobotanical study of a vessel content from Late Neolithic structured deposition from southeastern Hungary. Journal of Archaeological Science 40:58-71.

Piperno, D. 2006. Phytoliths. A Comprehensive Guide for Archaeologist and Paleocologist. Altamira Press, San Diego.

Planella, M., L. Quiroz, C. Belmar y V. McRostie 2009. Explorando el bosque esclerófilo: fitolitos y almidones de la flora nativa de Chile central. Resúmenes del XVIII Congreso Nacional de Arqueología Chilena, pp. 201-203. Gráfica LOM, Valparaíso.

Raviele, M. 2011. Experimental assessment of maize phytolith and starch taphonomy in carbonized cooking residues. Journal of Archaeological science 38:2708-2713.

Salazar, D., V. Figueroa, P. Andrade, H. Salinas, L. Olguín, X. Power, S. Rebolledo, S. Parra, H. Orellana y J. Urrea 2015. Cronología y organización económica de las poblaciones arcaicas de la costa de Taltal. Estudios Atacameños 50:7-46.

Sanhueza, J. 1985. Poblaciones tardías en playa "Los Verdes" costa sur de Iquique. I Región-Chile. Chungara 14:45-60.

Santana, F., J. Herrera y M. Uribe 2012. Acercamiento a la paleodieta en la costa y quebradas tarapaqueñas durante el periodo Formativo: análisis de isótopos estables a partir de tres casos de estudio. Boletín de la Sociedad Chilena de Arqueología 41/42:109-126.

Serrano, A. 1934. El uso del Tabaco y vegetales narcotizantes entre los indígenas de América. Revista Geográfica Americana 2(5):415-425.

Sinclaire, C. 2004. Prehistoria del período Formativo en la cuenca alta del río Salado (Región del Loa Superior). Actas XV Congreso de Arqueología Chilena. Chungara Revista de Antropología Chilena, Número Especial 2:619-639.

Spahni, J. 1967. Recherches archéologiques à l'embouchure du rio Loa (côte du Pacifique Chili). Journal de la Société des Américanistes 56:179-239.
Tarragó, M. 1989. Contribución al Conocimiento Arqueológico de las Poblaciones de los Oasis de San Pedro de Atacama en Relación con los otros Pueblos Puneños, en Especial del Sector Septentrional del Valle Calchaquí. Tesis de Doctorado en Historia, Especialidad Arqueología, Universidad Nacional de Rosario, Rosario.

Torres, C., D. Repke, K. Chan, D. Mackenna, A. Llagostera y R. Schultes 1991. Snuff powders from Pre-Hispanic San Pedro de Atacama: Chemical and contextual analysis. Current Anthropology 32:640-649.

True, D. 1975. Early maritime cultural orientations in prehistoric Chile. En Maritime Adaptations of the Pacific, editado por R. Casteel y G. Quimby, pp.89-143. Mounton Publishers, Paris.

Uribe, M. 2004. Alfarería, Arqueología y Metodología. Aportes y Proyecciones de los Estudios Cerámicos del Norte Grande de Chile. Tesis de Magíster en Arqueología. Universidad de Chile, Santiago.

Uribe, M. y P. Ayala 2004. La alfarería de Quillagua en el contexto formativo del Norte Grande de Chile (1000 a.C.-500 d.C.). Actas XV Congreso de Arqueología Chilena, Chungara Revista de Antropología Chilena Número Especial 2:585-597.

Uribe, M. y E. Vidal 2012. Sobre la secuencia cerámica del Período Formativo de Tarapacá (900 a.C. -900 d.C.): Estudios en Pircas, Caserones, Guatacondo y Ramaditas, Norte de Chile. Chungara Revista de Antropología Chilena 44:209-245.

Uribe, M. y E. Vidal 2015. Pottery and social complexity in Tarapacá: Reviewing the development of ceramic technology in the Atacama Desert (Northern Chile). En Ceramic Analysis in the Andes, editado por I. Druc, pp. 15-35. Deep University Press, Wisconsin.

Wilbert, J. 1976. La Metafísica del Tabaco entre los Indios de Sudamérica. Universidad Católica Andrés Bello, Caracas.

Willey, G. y P. Phillips 1958. Method and Theory in American Archaeology. University of Chicago Press, Chicago.

Wurschmidt, A. y M. Korstanje 1998-1999. Maíz en la cocina: primeras evidencias de fitolitos en sitios arqueológicos del NO Argentino. Cuadernos 18:457-468.
1 La cerámica Quitor se adscribe tradicionalmente al Período Medio (ca. 1.500-1.300 a.p.), aunque algunas de sus formas clásicas se ven asociadas también a tumbas con fechas previas o posteriores (Stovel 2013). Este período se expresa solo en San Pedro de Atacama, siendo sincrónico al Formativo regional. Para efectos de este artículo, consideramos la cerámica SNP como un sólo conjunto.

2 La mayor parte del material fue rescatado a modo de fragmentería, pero en varios casos fue posible la reconstitución de grandes segmentos de las vasijas, lo que junto con las piezas completas encontradas permitió una mejor comprensión de su morfología y huellas de uso (Correa 2017).

3 Si bien estos restos a veces se relacionan con procesos de contaminación postdepositacionales, la escasa presencia de esferulitas $(n=3)$ se da únicamente en un fragmento cerámico de la muestra, tal como se expresa en la Tabla 3. De tratarse de este tipo de contaminación, esta es mínima. Por otra parte, el ambiente de aridez extrema de los contextos aquí tratados, implican matrices de arena con prácticamente nulo material orgánico que pudiera actuar como contaminantes. 